\title{
PERCEPÇÃO DE GESTANTES SOBRE A ASSISTÊNCIA DE ENFERMAGEM REALIZADA DURANTE O PRÉ-NATAL DE RISCO HABITUAL
}

\section{PREGNANT WOMEN PERCEPTION ON NURSING CARE DURING HABITUAL RISK PRENATAL}

\section{CAREPERCEPCIÓN DE GESTANTES SOBRE LA ASISTENCIA DE ENFERMERÍA REALIZADA DURANTE EL PRENATAL DE RIESGO HABITUAL}

Bruna Raiane Dias ${ }^{1}$, Vania Aparecida Da Costa Oliveira ${ }^{2}$.

\begin{abstract}
RESUMO
Objetivo: Conhecer a percepção das gestantes vinculadas às equipes de Estratégia de Saúde da Família sobre a assistência de enfermagem realizada durante o pré-natal de risco habitual. Método: Estudo de caso com abordagem qualitativa. Participaram 18 gestantes cadastradas nas Estratégias de Saúde da Família de uma cidade do Centro-Oeste Mineiro, Brasil. A coleta de dados ocorreu de julho a agosto de 2018, por meio da associação de dois métodos, a análise documental e a entrevista semiestruturada. Para análise dos dados, utilizou-se a Análise Crítica do Discurso proposta por Normam Fairclough. Resultados: Observou-se que as gestantes percebem a assistência de enfermagem no pré-natal como momento de cuidado singular e propício à aprendizagem, atendendo às expectativas das gestantes e às recomendações presentes nos Manuais norteadores do Ministério da Saúde. Porém, notou-se também a presença de um discurso com base no modelo biomédico, centrado no tecnicismo e curativismo. Conclusão: $\mathrm{A}$ assistência de enfermagem à gestante vem sendo considerada como momento de singularidade do cuidado baseada no acolhimento e escuta. No entanto, algumas gestantes sentem-se inseguras quando acompanhadas pelo enfermeiro, o que revela um desconhecimento da capacidade técnica e científica desses profissionais e a hegemonia no modelo biomédico.

Descritores: Cuidado Pré-Natal; Saúde da Mulher; Cuidados de Enfermagem; Pesquisa Qualitativa.
\end{abstract}

\section{ABSTRACT}

Objective: to identifythe perception of pregnant women involved in the Family Health Strategy program concerning nursing assistance developed in low-risk prenatal care. Method: Case study with a qualitative approach, with 18 pregnant women registered in the Family Health Strategy program in a city of Minas Gerais State, Brazil. Data were collected in July and August 2018, from the association of two methods: documental analysis and semi structured interview, using Norman Fairclough's Critical Discourse Analysis proposal. Results: It was pointed out that pregnant women consider prenatal nursing assistance a singular care and suitable knowledge for the moment, satisfying their expectations and following the recommendations of the manual from the Brazilian Ministry of Health. However, a discourse based on technics and curative biomedical model was noticed. Conclusion: Nursing assistance to pregnant women has been considered a singular moment of care based on embracement and listening. Nevertheless, some pregnant women, based on biomedical model, feel insecure by the presence of a nurse, which reveals ignorance of those professionals scientific capacity.

Descriptors: Prenatal Care; Women's Health; Nursing Care; Qualitative Research.

\section{RESUMEN}

Objetivo: Conocer la percepción de mujeres embarazadas vinculadas a equipos de Estrategia de la Salud de la Familia sobre la asistencia de enfermería realizada durante prenatal de riesgo habitual. Método: Estudio de caso con abordaje cualitativo. Participaron del estudio 18 mujeres embarazadas registradas en Estrategias de Salud de la Familia de una ciudad de Minas Gerais, Brasil. La colecta de datos ocurrió de julio a agosto de 2018, por la asociación de dos métodos: el análisis documental y la entrevista semi-estructurada. Para el análisis de los datos, se utilizó el Análisis Crítico del Discurso, propuesto por Norman Fairclough. Resultados: Se observó que las mujeres embarazadas consideran la asistencia de enfermería en prenatal como un momento de cuidado singular y propicio al aprendizaje, lo que atiende a las expectativas de esas mujeres y las recomendaciones presentes en los manuales guía del Ministerio de la Salud. Sin embargo, se notó también la presencia de un discurso basado en el modelo biomédico, centrado en tecnicismo y tratamiento. Conclusión: La asistencia de enfermería a las mujeres embarazadas es considerada un momento de singularidad del cuidado, basado en acogida y escucha. Pero algunas de esas mujeres, basadas en el modelo biomédico, se sienten inseguras acompañadas del enfermero, lo que revela desconocimiento acerca de la capacidad científica de esos profesionales.

Descriptores: Atención Prenatal; Salud de la Mujer; Atención de Enfermería; Investigación Cualitativa.

${ }^{1}$ Enfermeira. Pós-graduação em Saúde da Família da Universidade Federal de São João del Rei. ${ }^{2}$ Enfermeira. Doutora em Enfermagem. Docente do Curso de Enfermagem da Universidade Federal de São João del Rei. 


\section{INTRODUÇÃO}

A gestação é um processo fisiológico em que, na grande maioria dos casos, acontece sem intercorrências. Cada mulher vivencia esse período de modo singular, necessitando de consultas sistematizadas que almejam a prevenção de possíveis agravos e a promoção da saúde da gestante e do feto ${ }^{(1)}$.

As consultas de pré-natal possuem diversos objetivos, como prevenir complicações na gestação e no parto, assegurar boa saúde materna, promover o bom desenvolvimento fetal, tratar ou controlar patologias e reduzir os índices de morbimortalidade materna e fetal. Realizar consultas de pré-natal sistemáticas e completas, de modo a alcançar os objetivos propostos, permite o desenvolvimento de um pré-natal de qualidade, refletindo em diminuição no número de complicações relacionadas ao período da gestação, além de aumentar o índice de satisfação da gestante e de seu parceiro com a assistência prestada ${ }^{(1-3)}$.

A taxa de mortalidade materna é um ótimo indicador do desenvolvimento da saúde em determinadas regiões. Sabe-se que, nos países desenvolvidos, essa taxa é de 12 óbitos maternos, por 100 mil nascidos vivos, enquanto nos países em desenvolvimento é de 239 óbitos maternos, por 100 mil nascidos vivos. O Brasil apresentou em 2014, 1.552 óbitos por 100 mil nascidos vivos, estando a região sudeste com uma taxa de 540 óbitos maternos, por $100 \mathrm{mil}$ nascidos vivos. Já, no estado de Minas Gerais, foram registrados 111 óbitos maternos por 100 mil nascidos vivos. Vários fatores contribuem para esse resultado, como a falta de adesão ao pré-natal, baixa escolaridade da gestante, gravidez durante a adolescência, fatores sociais, econômicos e demográficos, além das diversas transformações psicológicas, fisiológicas e econômicas que a gestante vive durante esse período ${ }^{(4)}$.

No Brasil, diversas estratégias foram desenvolvidas nos últimos 30 anos, com a finalidade de melhorar a qualidade da assistência e de reduzir as taxas de cesarianas e de mortalidade materna e neonatal. Em 2011, o Ministério da Saúde (MS) instituiu, no âmbito do Sistema Único de Saúde (SUS), a estratégia Rede Cegonha. Essa estratégia surgiu com a proposição de complementar e fortalecer o Programa de Humanização do Parto e Nascimento (PHPN), instituído em 2000. Dessa forma, a Rede Cegonha visa a organizar e estruturar a atenção de saúde materno infantil, por meio da garantia aos direitos da mulher ao Planejamento reprodutivo e atenção humanizada, durante todo o ciclo gravídico e puerperal, além de assegurar o direito de nascimento seguro e crescimento saudável das crianças ${ }^{(5)}$.

Nesse contexto, a consulta de enfermagem, no pré-natal, emerge como ferramenta importante no fortalecimento da assistência materno-infantil. Essa consulta é normatizada pela Lei do Exercício Profissional da Enfermagem, Decreto no 94.406/87, e reafirma a responsabilidade do enfermeiro ao realizar a consulta, prescrição e cuidados de enfermagem, oferecendo assistência integral à gestante de risco habitual, parturiente e puérpera, além de realizar atividades de educação em saúde ${ }^{(6)}$.

A consulta de enfermagem, durante o prénatal, vem sendo ressignificada, por meio de mudanças em sua metodologia e na sua inserção nos serviços de saúde, sobretudo na rede pública, sendo avaliada com boa aceitação por toda a enfermagem ${ }^{(3)}$. Essa assertiva é corroborada pela incorporação da Sistematização da Assistência de Enfermagem (SAE), pois, esta se constitui num método que guia a prestação da assistência de enfermagem para 0 melhor alcance de resultados. A utilização dessa metodologia tem permitido a visualização da gestante como um todo, por meio da otimização da coleta de dados que garante o estabelecimento de diagnóstico de enfermagem e suas respectivas intervenções. Além disso, torna-se necessária a avaliação dos objetivos alcançados, o que possibilitará o recomeço do processo, garantindo assim uma assistência cada vez mais individualizada ${ }^{(7)}$.

As consultas de enfermagem destacam-se na busca pela humanização no atendimento e pela garantia da assistência individualizada, de modo sistemático e amplo, proporcionando cuidado à gestante, durante o pré-natal, e, posteriormente, à puérpera e ao recém-nascido. Além dos aspectos relacionados à doença, a consulta de enfermagem, almeja o desenvolvimento de ações de educação em saúde, de modo a desenvolver a autonomia e o empoderamento das gestantes, a partir da troca de saberes, durante as consultas realizadas no pré-natal $^{(2,8)}$. No que tange às atividades estabelecidas em protocolos, destaca-se a coleta de dados referentes à idade, história clínica pregressa, histórico familiar, tabagismo, alcoolismo, atividades de lazer, contexto 
socioeconômico, exame físico e obstétrico, solicitação e avaliação de exames, prescrição de medicamentos estabelecidos em protocolos, levantamento de diagnostico, intervenções, avaliação das ações, dentre várias outras atividades ${ }^{(3)}$.

Paralelamente às mudanças ocorridas no campo da enfermagem, o SUS vem passando por transformações estruturais e organizacionais que visam à construção de um modelo de atenção à saúde mais justo, equânime, democrático, participativo, sendo assim, e sabendo que a enfermagem é uma ciência e tem como designo a realização de uma assistência de qualidade, por meio de ações de promoção da saúde, prevenção e recuperação de agravos, com foco no bemestar do indivíduo, família e coletividade humana é inquestionável a importância do usuário na avaliação das ações desenvolvidas por esses profissionais. Nas últimas décadas, tem se tornado crescente, na área da saúde, o interesse em conhecer a satisfação dos usuários quanto à qualidade da atenção recebida, sendo esse fator considerado como importante ferramenta na avaliação da assistência, visto que se trata da obtenção de opiniões dos próprios usuários ${ }^{(9)}$.

Diante do exposto e sabendo que as ações desenvolvidas pelo enfermeiro têm como foco o desenvolvimento de um cuidado de qualidade e, com base nas necessidades individuais de cada gestante, este estudo se justifica ao buscar opiniões e experiências vividas por gestantes frente à assistência de enfermagem, permitindo assim detectar os fatores relacionados à satisfação ou a insatisfação desse grupo.

Tornou-se objetivo deste estudo conhecer a percepção das gestantes vinculadas às equipes de Estratégia de Saúde da Família sobre a assistência de enfermagem realizada durante $o$ pré-natal de risco habitual.

\section{MÉTODOS}

Este trabalho constitui-se de um estudo de Caso com abordagem qualitativa. O estudo de caso caracteriza-se pela pesquisa incessante e exaustiva do objeto em estudo, permitindo alcançar o conhecimento detalhado e profundo sobre este. Destaca-se por sua capacidade de preservar o caráter único do objeto em estudo e, assim, potencializar a profundidade explicativa da análise do caso ${ }^{(10)}$.

O estudo foi desenvolvido em uma cidade do Centro Oeste Mineiro, Brasil, que possuía uma população de 213.016 habitantes no ano de
2010, com estimativa de 235.977 para o ano de 2018. O Município conta com 43 Unidades Básicas, sendo 32 Estratégias de Saúde da Família (ESF) e 11 Unidades Tradicionais, garantindo assim uma cobertura municipal de $46,99 \%$ da $\operatorname{ESF}^{(11)}$.

Inicialmente, a coleta de dados aconteceria, por meio de grupos focais, porém em razão da impossibilidade de realização dos grupos, uma vez que as gestantes não compareciam conforme agendamento telefônico, foi realizada uma alteração no projeto inicial. Assim, com a anuência do Comitê de Ética e Pesquisa, os dados foram coletados, por meio de análise documental e de entrevistas semiestruturadas.

Primeiramente, foi realizada uma análise documental buscando explorar os instrumentos nacionais direcionadores da assistência ao prénatal. Objetivou-se, com essa atividade, a construção de conhecimento que possibilitasse a compreensão das atividades preconizadas para essa assistência. A escolha dos documentos se deu após analisar aqueles que possuíam maior impacto e completude de informações, além da avaliação do ano de publicação. Sendo assim, os documentos que fizeram parte da análise documental foram de ordem Ministerial, Estadual e Municipal, sendo eles, respectivamente: o caderno de Atenção Básica no 32 intitulado "Atenção ao Pré-natal de baixo risco", publicado em 2012, "Atenção à saúde da gestante", publicado 2016 e o "Protocolo de atendimento ao pré-natal de risco habitual", publicado em $2018^{(12,13,14)}$.

Posteriormente, com a finalidade de identificar as Unidades de Saúde nas quais o enfermeiro realizava a consulta de pré-natal regularmente, durante todo o ciclo gravídico, foram realizadas ligações telefônicas a todas as Unidades Básicas, incluindo Unidades Tradicionais e ESF do Município. A partir dessa atividade, verificou-se que, em nenhuma das Unidades Tradicionais, o enfermeiro realizava a consulta de pré-natal sistematicamente, ou seja, esse profissional realizava somente a primeira consulta. Já no que diz respeito às 32 ESF existentes no Município, somente cinco possuíam essa atividade incorporada à rotina dos profissionais enfermeiros. Dessa forma, essas cinco ESF foram incluídas na coleta dos dados.

Após esse levantamento, a pesquisadora realizou visitas às cinco ESF, nos dias das consultas de pré-natal para efetuar a coleta dos 
dados. Além disso, foram realizadas visitas domiciliares às gestantes que, segundo os Agentes Comunitários de Saúde (ACS), poderiam estar em casa, naquele momento e participar da pesquisa. Assim, a coleta de dados ocorreu nas cinco ESF do Município, no período de julho a agosto de 2018, utilizando-se de entrevistas semiestruturadas, baseadas em um roteiro previamente elaborado, com o objetivo de direcionar a coleta de dados e, ao mesmo tempo, permitir às participantes discorrerem livremente sobre o assunto abordado ${ }^{(11)}$. A entrevista contou com perguntas referentes às atividades realizadas durante a consulta, sentimentos e avaliação das gestantes frente ao atendimento realizado pelo enfermeiro. Por fim, a gestante pode avaliar os aspectos facilitadores e dificultadores da consulta e discorrer livremente sobre assuntos que não foram perguntados, mas que mereciam destaque.

Foram incluídas no estudo, gestantes maiores de 18 anos vinculadas as ESF, nas quais o enfermeiro realiza consultas durante todo o ciclo gravídico. Foram excluídas da pesquisa aquelas gestantes que realizavam acompanhamento no Pré Natal de Alto Risco (PNAR).

$O$ estudo contou com seis entrevistas na ESF $A$, três em $B$, três em $C$, duas em $D$ e quatro em $E$, totalizando 18 entrevistas com recusa de participação somente de uma gestante que justificou não ter interesse em participar da pesquisa. Das entrevistas realizadas, sete ocorreram por meio de visita domiciliar e $11 \mathrm{em}$ consultórios disponibilizados nas próprias ESF. O número diferente de consultas entre as ESF se deve às particularidades de cada unidade, como o número de agendamentos de pré-natal, comparecimento das gestantes e a disponibilidade durante a visita domiciliar. A duração média das entrevistas foi de cinco minutos e 39 segundos. A coleta de dados foi interrompida após saturação dos dados.

Após a coleta de dados, os discursos foram transcritos na íntegra e com o objetivo de manter o anonimato das participantes, cada gestante foi nomeada pela letra " $E$ " seguida de um número aleatório e sua respectiva ESF identificada a partir de letras do alfabeto. Procurou-se conservar as características das falas, atentando-se para as manifestações verbais e não verbais das participantes. Para a análise dos dados, utilizouse a Análise Crítica do Discurso (ACD), proposta por Normam Fairclough que fundamenta-se na teoria social na qual o discurso é representado e influenciado pelo meio onde está sendo produzido, permanecendo inerente às influências sociais, políticas, históricas, culturais e econômicas $^{(15)}$.

Dessa forma, após a transcrição das entrevistas, procurou-se realizar uma análise compreensiva dos discursos, buscando identificar discursos semanticamente semelhantes e repetidos, ao longo dos textos, dando origem assim às categorias empíricas. Atentou-se, durante a análise dos dados, a identificação das mudanças na entonação da voz, pausas durante as falas, arquitetura textual e uso de pronomes durante os relatos. Por fim, buscou-se relacionar os achados com a literatura já existente, possibilitando validar as informações obtidas.

A pesquisa foi aprovada pelo Comitê de Ética em Pesquisa Envolvendo Seres Humanos CEPCO do Campus Centro-Oeste, Dona Lindu, da Universidade Federal de São João del-Rei, sob parecer CAAE: 2.642.515.Todos os preceitos éticos foram respeitados, sobretudo o direito ao anonimato das depoentes, em consonância com a Resolução no 466/2012, do Conselho Nacional de Saúde (CNS), que regulamenta a pesquisa com seres humanos no Brasil ${ }^{(16)}$.

\section{RESULTADOS E DISCUSSÃO}

As 18 gestantes que participaram do estudo tinham entre 18 e 35 anos e uma média de idade de 26,6 anos. 4 gestantes encontravamse no primeiro trimestre, 5 no segundo e 9 no terceiro.

A partir da análise dos dados emergiram quatro categorias empíricas, a saber: A dimensão educativa da consulta de enfermagem no momento do pré-natal, a dimensão do cuidar na consulta de enfermagem no pré-natal como possibilidade de cuidado singular e atividades desenvolvidas na consulta do enfermeiro à gestante.

\section{Categoria 1: A dimensão educativa da consulta de enfermagem no momento do pré-natal}

A gestação é um processo fisiológico e, ainda que durante esse período a mulher passe por diversas mudanças físicas, psicológicas, sociais e emocionais, essa etapa deve ser vista como parte de uma experiência de vida saudável, cabendo ao profissional de saúde orientar quanto às transformações inerentes a esse período ${ }^{(17)}$.

Nesse contexto, várias participantes apontaram os grupos de gestante como espaço importante para a retirada de dúvidas e para 
realização de orientação quanto ao processo gestacional e as alterações vivenciadas. Estas afirmações são corroboradas conforme demonstrado nos relatos a seguir:

[...] "Sim, a enfermeira sempre explicou tudo que precisava, nunca deixou nada em dúvida [...]. Teve uma palestra que ela fez, acho que ela deu acompanhamento com as outras gestantes que estavam lá [...](E1- ESF A)

[...] "Ela tirou minhas dúvidas, fez tudo direitinho [...]. todo mês tinha palestra, sempre eram as enfermeiras que faziam" [...]. (E2- ESF A)

[...] "Ela tirou muita dúvida que eu tinha, deram palestra antes do pré-natal com 0 médico[...].As dúvidas que eu tinha a enfermeira respondeu tudo certinho [...]. No posto, nos dias do pré-natal, tem as palestras que elas fazem antes de consultar com o médico, tiram muitas dúvidas"[...]. (E4-ESF A)

[...] "Ela mata um tanto de curiosidade da gente, igual teve uma vez que eu fui lá só porque ele não tava mexendo, ela olhou e explicou que era normal, eu pensei que já era outra coisa" [...] (E15-ESF E)

A assistência de qualidade prestada à gestante durante o pré-natal, quando baseada no acolhimento e atividades de orientação, direcionam para o empoderamento da mulher, garantindo assim a humanização do cuidado e o fortalecimento da atenção básica. Tais características de atendimento, quando percebidas pelas gestantes, tendem a estabelecer uma maior confiança, contribuindo para a adesão as ações propostas e para melhoria da qualidade de assistência ${ }^{17}$. Essa afirmação é corroborada pelos discursos de E1-ESF A, E2-ESF A, e E4-ESF A que apresentam uma repetição do pronome indefinido "tudo", que nos remete a concepção de totalidade e completude nos atendimentos, transmitindo a ideia de satisfação da gestante que, por diversas vezes, afirma que as atividades foram inteiramente realizadas, atendendo, assim, as suas expectativas. Já E15-ESFE, ao utilizar a expressão "Ela mata um tanto de curiosidade(...)" procura por meio de sua fala, dar ênfase ao número significativo de dúvidas que são esclarecidas pela enfermeira, garantindo maior segurança no decorrer da gestação ${ }^{(9,15)}$.

Percebe-se que, muitas vezes, a figura do enfermeiro apresenta-se entrelaçada a função de educador, tanto no que se refere aos atendimentos em grupo, conforme apontado por E1-ESF A, E2-ESF A e E4-ESF A, quanto nas consultas individuais, conforme também foi evidenciado nos discursos a seguir:

[...] "A função da enfermeira eu não sei totalmente, mas ajuda muito, igual nessa questão de exame, tirar dúvidas, elas sabem muita coisa" [...] (E4-ESF A).[...] "Orientar, orientar, né? ver se tá tudo bem com a criança, bem dizer é para isso." [...] (E6-ESF A)[...] "Acho que a função do enfermeiro é ajudar nesse momento, dar conselhos também, né?" [...](E12-ESF C).

Observa-se, no discurso de E4-ESFA, a utilização do pronome de intensidade "muito", relacionado às ações de orientação e disseminação do saber do enfermeiro, destacando-se ainda como uma valorização do conhecimento científico desse profissional. Por outro lado, a utilização das expressões "eu não sei totalmente" e "né?" somadas a pausa das gestantes frente à indagação quanto a função do enfermeiro, demonstram uma dificuldade de resposta e incerteza no discurso apresentado pelas entrevistadas, revelando um desconhecimento da função do enfermeiro nesse contexto ${ }^{(15)}$.

Estudo aponta que o enfermeiro é um profissional que possui papel importante nas ações de prevenção e promoção da saúde, ocupando posição de destaque dentre as categorias profissionais atuantes na assistência ao pré-natal. Merecendo ênfase, a habilidade em utilizar a escuta atenciosa e o vínculo, este último relaciona-se a aproximação entre profissionais e usuários, reforçando a importância da corresponsabilidade entre eles, como ferramentas importantes na identificação de problemas, estabelecimento de prioridades e definição de ações a serem desenvolvidas, de maneira que ocorra uma melhora na qualidade de vida da mãe em busca de uma gravidez e um parto sem intercorrências ${ }^{(18)}$.

Outro aspecto evidenciado nos discursos das gestantes é a comunicação entre elas, proporcionada pelas atividades grupais de educação em saúde, oportunizando a troca de saberes e garantindo maior empoderamento frente às situações vivenciadas durante a gestação e também o pós-parto.

[...] "Eu acho importante as palestras porque a gente troca ideia, a gente aprende, né? Nunca é demais aprender! Elas orientam a gente, tiram dúvidas." (E5-ESF A)

[...] "Sempre tem um tema, por exemplo, cuidados com o bebê, sinais de preparação pro parto (...) a gente sempre tem coisa pra 
aprender, uma troca ideia com a outra" [...] (E6ESF A).

[...] "No grupo tem mais gente e às vezes alguém pergunta o que você queria perguntar, mas não sabia formular a pergunta, não sei [...]Eu gostava bastante" [...] (E11-ESFC).

Percebe-se, por meio dos discursos de E5ESF A, E6-ESF A e E11-ESF o enaltecimento das atividades realizadas em grupo, uma vez que as gestantes valorizam a troca de saberes e complementariedade das dúvidas. Nota-se, também, a utilização de expressões como "nunca é demais aprender" e "sempre tem coisas pra aprender", tais termos emitem a ideia de novidade e necessidade de orientações contínuas, visto que as gestantes reconhecem a indispensabilidade de aprendizagem e atualização de conhecimentos ${ }^{(17)}$.

Sabe-se que a mulher tende a estar mais atenta às orientações durante o período gestacional, o que potencializa a necessidade de oferecer ações educativas que capacitem a gestante para a realização do autocuidado. Nesse contexto, a atenção pré-natal adquire o compromisso de atender às inúmeras necessidades que podem surgir no decorrer do processo gestacional, além de realizar ações de incentivo à adoção de comportamentos que estão intimamente relacionados ao desenvolvimento saudável de uma gestação, compreendendo assim todas as ações de educação em saúde. Sabe-se que as ações educativas possibilitam à mulher a conhecer o seu corpo, diminuindo as inseguranças, medos e ansiedades e que as abordagens grupais favorecem a interação entre as gestantes, especialmente quando se utilizam as tecnologias leves em saúde, como o acolhimento, responsabilização e o vínculo(1).

\section{Categoria 2: A dimensão do cuidar na consulta de enfermagem no pré-natal como possibilidade de cuidado singular}

Durante suas atividades, os profissionais de saúde devem fazer uso de uma escuta qualificada, com base no acolhimento das necessidades individuais das gestantes. Esse recurso compreendido como tecnologias leves são importantes no fortalecimento das relações interpessoais e dos programas ancorados no referencial de atenção ao pré-natal. Entende-se tecnologia leve como sendo aquela referente a relação entre sujeitos, como acolhimento, vínculo e compartilhamento do cuidado. Nessa ótica, tem-se o cuidado, conhecido como a essência do trabalho do enfermeiro, que vem sendo incorporado a assistência saúde da mulher no ciclo gravídico puerperal, variando entre uma abordagem tecnicista a uma visão mais humanística $^{(19)}$.

Durante a análise dos discursos, notou-se uma valorização no que se refere às ações de acolhimento e escuta desenvolvidas pelo enfermeiro, enfatizando a importância da individualidade do cuidado para o desenvolvimento de um pré-natal saudável, conforme demonstrado a seguir:

[...] "Eu vejo mais ponto positivo na consulta, negativo eu ainda tenho não. Até hoje elas me atenderam super bem!" [...].(E7-ESF B)

[...] "São muito atenciosos, explicam muito a gente!" [...]. (E8-ESF B)

[...] "Eu não vejo nenhum ponto negativo. As meninas [enfermeiras] são muito atenciosas, procuram atender direitinho e tem paciência para escutar as nossas dúvidas [...]. Eu acho que elas deixam a gente bem tranquila" [...].(E13-ESF D)

[...] "Eu achava que [com enfermeira] era mais bem atendido e a atenção era maior, aquele carinho de te mostrar as coisas. Também varia de enfermeiro para enfermeiro, né?" [...]. (E14ESF D)

[...] "Tenho nada que reclamar, foram muito atenciosos [...]. Ah! Não tem nada negativo, positivos são muitos. Eles falam com honestidade com a gente, não mente" [...]. (E18ESF E)

Nos trechos apresentados, identifica-se a utilização de advérbios de intensidade como "bem" e "muito" que conferem à proposição um grau maior de efetividade, ou seja, por meio dos discursos de E7-ESF B, E8-ESF B, E13-ESF D e E18ESF $E$, torna-se evidente o efeito satisfatório frente a escuta atenciosa e atendimento realizado pelos enfermeiro ${ }^{(15)}$.

Ainda em relação ao cuidado individualizado e de qualidade, destaca-se a Rede Cegonha que preconiza o desenvolvimento de ações de organização da atenção materna e infantil.

Pautadas na garantia de acesso, acolhimento e resolutividade desenvolvidas neste período, além de atividades que buscam a humanização do atendimento como indispensáveis para o desenvolvimento de uma gravidez, parto e pós parto adequados, envolvendo familiares e o contexto familiar e o 
ambiente sociocultural ${ }^{(5,20)}$. Nesse contexto, destacamos os dizeres a seguir :

"Eu senti segurança sim, eu gosto muito da enfermeira que tem aqui, tudo que você pergunta ela responde direitinho e eu tinha muitas dúvidas [...]. Uma gravidez não é igual a outra!" [...].(E5-ESF A)

[...] "As enfermeiras daqui do posto já conhecem a gente, elas sabem quando a gente não tá bem [...]. A gente pegou uma certa amizade, então a gente tem mais intimidade do que com o médico, até mesmo por ser mulher, né?" [...].(E6-ESF A)

[...] "Elas sempre me trataram super bem. Tem unidade que eles não preocupam muito, mas aqui sempre estão ligando [...]. A gente tem agente comunitário, aí ela vem pergunta ou liga pra saber se tá acontecendo alguma coisa" [...]. (E17-ESF E)

As falas apresentadas por E5-ESF A, E6-ESF A e E17-ESF E destacam-se por transmitirem uma relação de confiança estabelecida entre 0 enfermeiro e as gestantes, evidenciadas pelas expressões "a gente pegou uma certa amizade", "tem unidade que elas não preocupam muito, mas aqui sempre estão ligando" ou ainda, "gosto muito da enfermeira". Tais afirmações vão em direção as orientações do Ministério da Saúde que destacam a criação do vínculo como ferramenta essencial nas atividades da Atenção Primária à Saúde (APS) e principalmente no prénatal ${ }^{(4,8)}$.

Sabe-se que a criação do vínculo abre portas para a avaliação de outro fator importante durante a assistência de pré-natal, qual seja, o contexto social e familiar vivenciado pela gestante. As mudanças no contexto familiar influenciadas pelas próprias crenças, valores e costumes podem interferir no período gestacional, sendo assim, cabe ao profissional de saúde reconhecer o contexto em que a gestante vive com vistas a desenvolver um cuidado individualizado, respeitando suas crenças e costumes sem julgamento de valor ${ }^{(1)}$.

Outro fator destacado nos discursos de E5ESF A e E6-ESF A relaciona-se ao preenchimento do prontuário e da caderneta da gestante durante a consulta do enfermeiro. Evidenciou-se que nas consultas, esse profissional procurava preencher os campos de maneira completa, evitando os espaços vazios, valorizando a singularidade das gestantes e atentando-se as informações consideradas como essenciais, conforme os excertos a seguir:
[...] “Ó na minha consulta com o enfermeiro ela fez praticamente a mesma coisa que o médico, foi até melhor que a do médico porque ela anotou tudo na cadernetinha e geralmente os médicos esquecem de anotar e o enfermeiro pela eficiência que eles querem fazer as coisas bem feitinha, inclusive minha cadernetinha tava até em branco." (E5-ESF A)

[...] "A caderneta tava com muito espaço em branco, e assim, o enfermeiro preencheu tudo, fez com mais calma, faz até pergunta que o médico não faz (E6-ESF A)

[...] "Eu avalio a consulta como muito boa, eu acho que o enfermeiro pergunta bastante, eles tem mais interesse em perguntar, em saber, escreve lá nas fichas, acho interessante. Eu gosto, acho boa!" [...]. (E12-ESF C)

Observa-se na fala de E5-ESF A e E6-ESF Aa utilização da expressão "bem feitinha" e "preencheu tudo", respectivamente, que referese à atividade de preenchimento da caderneta utilizada como forma de avaliação positiva da consulta de enfermagem, uma vez que as gestantes entendem e valorizam essa atividade. Ainda no que se refere à escuta qualificada e o cuidado individualizado E12-ESF C utiliza o advérbio de intensidade "muito" seguido do adjetivo "boa" na avaliação positiva das consultas de enfermagem ${ }^{(15)}$.

O Ministério da Saúde preconiza a realização de procedimentos que são considerados essenciais durante a assistência ao pré-natal, como por exemplo, o preenchimento da caderneta e o registro no prontuário da gestante. Nesse sentido, o cartão da gestante é definido como um instrumento de registro, de posse da gestante, que deve conter os principais dados de acompanhamento da gestação, sendo esta uma das maneiras de documentar as informações de realização, avaliação e conduta das atividades durante o pré-natal. Além disso, entende-se que o cartão da gestante atua como ferramenta de comunicação entre os diversos profissionais de saúde que acompanham a mulher durante o pré-natal, sendo essencial para o fluxo de referência e a contra referência na rede de saúde ${ }^{(12)}$.

Em estudo que buscava avaliar o grau de completude do preenchimento do Cartão da Gestante em um hospital universitário, foi observada uma realidade semelhante à relatada pelas gestantes entrevistadas. Neste estudo, verificou-se uma lacuna no processo assistencial durante o pré-natal frente a procedimentos 
básicos, evidenciando que as atividades estariam deixando de ser realizados ou registrados. Mais grave ainda é a omissão de registro de várias informações simples, como idade, antecedentes clínicos e obstétricos, curva de peso, IMC, altura uterina, apresentação fetal e situação vacinal ${ }^{(21)}$.

Em contraponto, tem-se que a responsabilidade do profissional para com 0 estado de saúde do usuário é um dos elementos fundamentais para um atendimento eficaz. Além disso, estimula no usuário sentimento de confiança em relação ao profissional que realiza a assistência ${ }^{(22)}$.

\section{Categoria 3: Atividades desenvolvidas na consulta do enfermeiro à gestante}

Durante a gestação a mulher passa por diversas transformações, sendo necessário o acompanhamento por um profissional de saúde. Estes, após avaliação meticulosa da gestante, classificam o risco gestacional, aquelas que apresentarem gravidez de risco habitual poderão ser acompanhadas na atenção primária, com suporte multiprofissional, com destaque aqui para as consultas do enfermeiro ${ }^{(8)}$.

Conforme já expresso, a consulta de enfermagem no pré-natal tem como objetivo a promoção da saúde e prevenção de agravos, constituindo-se de condutas e procedimentos em favor do binômio mãe e filho. Com esse propósito são desenvolvidas diversas ações durante o período gestacional, sendo atribuições do enfermeiro, segundo o Ministério da Saúde (2015): cadastramento da gestante no SisPréNatal, preenchimento e atualização do cartão da gestante, solicitação de exames complementares de acordo com os protocolos locais, execução de testes rápidos; prescrição de medicações conforme protocolos, orientação quanto à situação vacinal, identificação sinais de alarme, realização exame clínico das mamas, coleta exame colpocitológico, realização de visitas domiciliares, entre outros ${ }^{(3,12)}$.

A seguir, destacam-se algumas falas referentes às atividades desenvolvidas pelo enfermeiro, mencionadas pelas gestantes durante as entrevistas:

[...] "Medir a altura do feto, ouvir os batimentos do coração e olhar os exames [...]. Ela via a posição do bebe e fazia a medição da barriga" [...]. (E1-ESF A)

[...] "Medir pressão, escutar coração, medir a barriga. Foi tranquilo!" [...]. (E2-ESF A)
[...] "Bom, sou sempre bem atendida, né? Mede a pressão, pergunta como passou o mês, se tem alguma queixa, mede a barriga, escuta o coraçãozinho da criança, pergunta sobre a alimentação como que tá e passa os exames que você tem que fazer no próximo mês" [...]. (E12ESF C)

[...] "Tirando pressão, pesando, olhando meu remédio" [...]. (E8- ESFB)

Observa-se nos relatos de E1-ESF A,E2-ESF $A$ e E8-ESF $B$ uma dificuldade em descrever as atividades realizadas durante as consultas, verificada a partir de uma pausa significativa entre a pergunta e a resposta. ${ }^{15}$ Nesse sentido, verifica-se que inúmeras atividades preconizadas não foram mencionadas durante a entrevista, sendo difícil inferir se este fato se deve a não realização das atividades ou dificuldade das gestantes em rememorar as ações. Porém, baseando-se nas atividades relatadas e tendo como referência os manuais utilizados no referencial teórico deste trabalho, verifica-se que as atividades apontadas pelas gestantes são padronizadas como essenciais para esse público, constituindo-se como ferramentas indispensáveis na assistência ao pré-natal ${ }^{(12,14)}$.

Estudo aponta que nas últimas décadas a utilização de protocolos e manuais pela enfermagem tem contribuído para o aperfeiçoamento e padronização das atividades realizadas, sendo considerado pelos profissionais como essencial para o êxito do pré-natal. Em contrapartida percebe-se que alguns profissionais desvalorizam e apresentam resistência na implantação destes ${ }^{(3)}$.

Ainda em relação às atividades realizadas durante as consultas, percebe-se o estabelecimento de procedimento técnicos como, aferição de pressão arterial, medida da altura uterina, avaliação dos batimentos cardíacos fetais, avaliação do peso e do índice de massa corporal, entre outros, considerados como essenciais na prevenção, identificação e correção de riscos à saúde materno-fetal ${ }^{(22)}$.

Dentre as atividades desenvolvidas durante o exame clínico, destaca-se aqui a avaliação do peso e altura, com posterior cálculo do Índice de Massa Corporal (IMC), conforme presente no excerto a seguir:

[...] "Durante a gravidez eu ganhei um pesinho, 20 quilos [...]. Quando eu ia consultar com o médico ele falava que tava bom, mas a enfermeira pedia pra eu tomar cuidado que meu peso tava aumentando [...].(E5-ESF A) 
Verifica-se em estudo que entre os itens avaliados no preenchimento da caderneta gestacional, a avaliação de peso e IMC salienta-se pelo baixo índice de preenchimento, levando a inferir a desvalorização desse item, durante o período gestacional. É sabido que o ganho de peso excessivo, durante esse período, associa-se com maior incidência de complicações obstétricas, além de estar sendo considerado como fator de risco para a obesidade feminina ${ }^{(21)}$.

Outro fator de destaque relaciona-se ao fato de que apesar do reconhecimento pelo Ministério da Saúde e Conselho Federal de Enfermagem da regularidade do acompanhamento realizado pelo enfermeiro, durante todo o ciclo gravídico puerperal nos casos de gravidez de risco habitual, observa-se uma dificuldade de aceitação da população e, por vezes, até mesmo dos profissionais de saúde em aceitar as consultas dos enfermeiros. O motivo relaciona-se com o modelo biomédico que coloca a assistência a saúde de modo hegemônico para medicina, inspirados pelo tecnicismo e curativismo $^{(8)}$. A seguir destacam-se os discursos que corroboram com essa informação:

[...] "Por ser o pré-natal, às vezes a gente se senti mais segura quando a consulta é com o médico, pela formação dele. Por mais que a enfermeira seja como ele. Para mim é importante ser o médico todo mês. Já no final quando a consulta é a cada 15 dias eu não vejo problema nenhum [...].A diferença ta na formação, né?" [...]. (E2- ESF A)

[...] "O que ela fez foi satisfatório. Me explicou direitinho, me explicou a respeito do cartão de pré-natal me informou que meu marido também poderia vim [...]. Na primeira consulta eu me senti segura [...]. por ser a primeira eu acho que é meio padrão, mas e se eu tivesse sentindo essa dor, ela ia detectar a infecção de urina? Será que ela ia poder me prescrever o antibiótico?" [...]. (E10- ESF C)

[...] "Uai, a função do enfermeiro é atender o paciente mesmo, ajudar o médico a atender o paciente. (E12- ESF C)

Evidencia-se, por meio dos relatos de E2ESF A e E10-ESF C uma desconfiança frente aos atendimentos de enfermagem, durante o prénatal, apontada pelas gestantes como possíveis de serem realizadas com segurança somente na primeira consulta ou no final do período gestacional, quando estas começam a acontecer com intervalos menores. Verifica-se, nesses excertos, a presença de interdiscurso observado a partir de falas que evidenciam o discurso da hegemonia médica em detrimento de outras profissões da área da saúde, muito comum no modelo médico centrado ${ }^{(15)}$.

Chama-se atenção para o discurso da gestante E12 - ESF C que evidencia o impacto inicial, referente ao desconhecimento da competência e habilidade do enfermeiro para desenvolver esse trabalho, como pode ser observado a seguir:

[...] "Nos primeiros dias eu não me senti segura, mas aí depois eu vi que o enfermeiro era tão capacitado quanto o médico, aí eu me senti legal [...]. No primeiro dia que eu vim aqui me falaram que era com enfermeira. Aí eu já não queria vim, mas quando ela me atendeu, ela já fez os testes e foi me explicando o que tinha que fazer. Ai eu gostei" [...]. (E12- ESF C).

E12-ESF $C$ ao utilizar a conjunção adversativa "mas" demonstra que no início das consultas desconhecia a capacidade técnica e científica do enfermeiro, porém, ao longo dos atendimentos, ela passou a confiar neste profissional, pois à medida que a gestante é atendida e esclarecida, ela tende a confiar e adquirir segurança no profissional ${ }^{(7)}$.

Esse cenário reflete o modelo biomédico que ainda se mostra como o grande influenciador nos serviços de saúde e na população. Contudo, as diretrizes da ESF, emergem para ordenar novo modelo assistencial, não mais pautado na doença e na hegemonia médica, mas nas condições ampliadas de saúde da população e com foco em toda a equipe multidisciplinar ${ }^{(23,24)}$.

Reorientar o modelo de saúde é missão árdua e que caminha devagar. Entretanto, as modificações se iniciam a partir da assistência de qualidade prestada por profissionais que modificam a cultura do serviço em que se encontram inseridos e da população atendida. Nessa luta pela mudança do sistema de saúde, ainda incipiente, observa-se que os enfermeiros ao atenderem as gestantes no pré-natal, conquistam a confiança delas e, com isso, criam perspectivas de mudança de cultura e contribuem para um maior reconhecimento, por parte da população, sobre 0 atendimento prestado, ressignificando assim, a consulta de enfermagem $^{(23,24)}$.

\section{CONSIDERAÇÕES FINAIS}

Observou-se com essa investigação que a assistência de enfermagem à gestante vem sendo considerada como momento de cuidado singular, 
baseado no acolhimento, na escuta e fortalecida por meio do vínculo entre gestante e enfermeiro, além de proporcionar momentos em grupo que favorecem o compartilhamento de dúvidas e saberes. Evidenciou-se que as ações desenvolvidas pelo enfermeiro, durante a consulta de pré-natal estão alinhadas às recomendações dos manuais norteadores e à literatura disponível, o que tende a favorecer a melhoria da qualidade da assistência prestada. Por outro lado, verificou-se que algumas gestantes, influenciadas pelo modelo biomédico, sentem-se inseguras diante da consulta de enfermagem, avaliando como essencial o atendimento médico durante todo o ciclo gravídico.

Nota-se, ainda, que a existência de marcos legais, como leis e políticas governamentais são necessárias para subsidiar a assistência realizada pelo enfermeiro, assim como contribuir para uma assistência de qualidade e garantir maior reconhecimento do enfermeiro frente às ações desenvolvidas durante a assistência ao pré-natal.

Por fim, observa-se que as ações do enfermeiro, em sua grande maioria, vêm caminhando com prestígio e aceitação pelas gestantes que percebem de maneira positiva a participação desse profissional na assistência gestacional.

Acredita-se que este estudo possa contribuir de modo singular para a assistência de enfermagem no pré-natal. Ao refletir sobre o modo em que as gestantes observam a assistência recebida, os enfermeiros podem ressignificar sua assistência, fortalecendo os aspectos positivos evidenciados pelas gestantes e amenizando ou retirando da sua prática profissional os aspectos negativos. Possibilitando, dessa forma, o fortalecimento da enfermagem em detrimento do modelo médico centrado.

Salienta-se, como limitação deste estudo, a sua realização apenas nas ESF de uma cidade do Centro Oeste Mineiro. Portanto, sugere-se que novos estudos sejam realizados em outras cidades e cenários, assim como novos estudos sobre essa temática, pois se acredita que esta é de extrema importância para a saúde da mulher.

\section{REFERÊNCIAS}

1 - Alves CN, Wilhelm LA, Barreto CN, et al. Cuidado pré-natal e cultura: uma interface na atuação da enfermagem. Esc Anna Nery - Rev Enferm. 2015;19(2):265-271. Available in: http://www.scielo.br/scielo.php?script=sci artte xt\&pid=S1414-81452015000200265

2 - Camillo BS, Nietsche EA, Salbego C, et al. Health education actions in primary attention to pregnant and puerperal women: integrative review. J. Nurs UFPE/Rev Enferm UFPE on line.2016; 10(6):4894-4901. Available in: https://periodicos.ufpe.br/revistas/revistaenferm agem/article/view/11270

3 - Oliveira EC de, Barbosa S de M, Melo SEP. A importância do acompanhamento pré-natal realizado por enfermeiros. Rev Cient FacMais. 2016;7(3):24-38. Available in http://revistacientifica.facmais.com.br/wpcontent/uploads/2017/01/Artigo-02-Aimportância-do-acompanhamento-pré-natalrealizado-por-enfermeiros.pdf 4- Martins ACS, Silva LS. Perfil epidemiológico de mortalidade materna.Rev Bras Enferm.2018;71(1):725-731. Available in: http://www.scielo.br/pdf/reben/v71s1/pt 00347167-reben-71-s1-0677.pdf

5 - Lopes GDC, Gonçalves AC, Gouveia HG, Armellini CJ. Attention to childbirth and delivery in a university hospital: comparison of practices developed after Network Stork. Rev. Latino-Am. Enfermagem. 2019;27:e3139. Available in: http://www.scielo.br/scielo.php?pid=S0104$11692019000100327 \&$ script $=$ sci arttext\&tIng=pt 6 - Baptista RS, Dutra MOM, Coura AS. Assistência pré-natal: ações essenciais desenvolvidas pelos enfermeiros. Enferm. glob. 2015(40):112-127 Available in: http://scielo.isciii.es/pdf/eg/v14n40/pt clinica5.pdf 7 - Suhre PB, Costa AEK, Pissaia LF, Moreschi C. Sistematização da assistência de enfermagem: percepções de gestantes acompanhadas em uma unidade básica de saúde. Espaço Ciência \& Saúde. 2017;5(1):20-31. Available in: http://www.revistaeletronica.unicruz.edu.br/ind ex.php/enfermagem/article/viewFile/5488/1054 8 - De Andrade FM, De Lima Castro JF, Da Silva AV. Percepção das gestantes sobre as consultas médicas e de enfermagem no pré-natal de baixo risco. Rev. enferm. Cent.-Oeste Min.2016;6(3):2377-2388. Available in: http://www.seer.ufsj.edu.br/index.php/recom/ar ticle/view/1015

9 - Luis T, Barbosa DA, Dias OV. O Pré-Natal Realizado Pelo Enfermeiro: a Satisfação Das Gestantes.Cogitare Enferm.2011;16(1):29-35. Available https://revistas.ufpr.br/cogitare/article/viewFile/ 21108/13934 
10 - Gil A. Como elaborar projetos de pesquisa.5a ed. São Paulo: Atlas; 2010. Available in: https://acervodigital.ssp.go.gov.br/pmgo/bitstrea $\mathrm{m} / 123456789 / 427 / 7 /$ Livro\%20-

\%20Como\%20Elaborar\%20Projetos\%20de\%20Pes quisa\%20-

\%20Como\%20Delinear\%20Um\%20Estudo\%20de \%20Caso\%20-\%20Cap\%C3\%ADtulo\%202.pdf

11 - Informação e Gestão da Atenção Básica[homepage na internet].Cobertura de Atenção Básica- DAB[acesso em 02 dez de 2018]. Available in: https://egestorab.saude.gov.br/paginas/acessoP ublico/relatorios/relHistoricoCoberturaAB.xhtml 12 - Ministério da Saúde (BR). Secretaria de Atenção à Saúde. Departamento de Atenção Básica. Brasília: Ministério da Saúde, 2013. Available in: http://www.rio.ri.gov.br/dlstatic/10112/6536378 4175300/23CAP32 prenatal.pdf

13 - Secretaria de Estado de Saúde de Minas Gerais (MG). Atenção à saúde das gestantes, 2016. Available in: http://www.saude.mg.gov.br/images/documento s/16-03-10-Cartilha-Estratificao-de-riscogestacional.pdf

14 - Secretaria Municipal de Saúde. Protocolo de Atenção ao Pré natal de Risco Habitual. Divinópolis (MG); 2018.

15- Fairclough N. Discurso e mudança social. 2a ed. Brasília: Universidade de Brasília; 2016. Available

in:

https://www.academia.edu/5281166/Discurso e Mudan\%C3\%A7a Social - Norman Fairclough 16 - Brasil. Resolução 466, de 12 de dezembro de 2012. Aprova as diretrizes e normas regulamentadoras de pesquisa envolvendo seres humanos. Conselho Nacional de Saúde. 2012 dez. 12. Available in: http://bvsms.saude.gov.br/bvs/saudelegis/cns/2 013/res0466 $1212 \quad$ 2012.html

17 - de Araújo Gama G, Soares Figueiredo Trezza MC, da Silva Rodrigues PM, et al.Health promotion in pregnancy: enforcement of nola pender theory on prenatal care.Rev Enferm UFPE on line. 2016;10(5):4428-4431. Available in: https://periodicos.ufpe.br/revistas/revistaenferm agem/article/view/11197

18 - Santos RLB, Prestes M, Meincke SMK, et al. Atenção no pre natal de baixo risco na ótica de puérperas. Rev. enferm. UFSM. 2015;5(4): 628-637. Available in: https://periodicos.ufsm.br/reufsm/article/view/16071 19 - Merhy EE, Baduy RS, Seixas CT, et al.
Avaliação compartilhada do cuidado em saúde:Surpreendendo o instituido nas redes. 1a ed.Rio de Janeiro: Ali Celestino;2016. Available in: file://C:/Users/User/Downloads/Livro1completo Avaliacao compartilhada vol1 web.pdf 20 - Ortigara EP de F, Carvalho MD de B, Pelloso SM. Percepção da assistência pré-natal de usuárias do serviço público de saúde. Rev. enferm. UFSM. 2015;5(4):618-627. Available in: https://periodicos.ufsm.br/reufsm/article/view/1 $\underline{3230}$

21 - Coelho T, Medeiros A, Ribeiro W, Menezes T. Avaliação do Grau de Completude do Cartão da Gestante de Puérperas Atendidas em um Hospital Universitário. Rev. Bras. Ciências da Saúde. 2015;19(2):117-122. Available in: http://www.periodicos.ufpb.br/ojs/index.php/rb cs/article/view/22098

22 - Nunes JT, Gomes KRO, Rodrigues MTP, et al. Qualidade da assistência pré-natal no Brasil: revisão de artigos publicados de 2005 a 2015. Cad. Saúde Colet. 2016;24(2):252-261.Disponível: http://www.scielo.br/pdf/cadsc/v24n2/1414462X-cadsc-24-2-252.pdf

23 - Esmeraldo GR de OV, Oliveira LC de, Filho $\mathrm{CEE}$, et al. Tensão entre o modelo biomédico e a estratégia saúde da família: $A$ visão dos trabalhadores de saúde. Rev. APS. 2017;20(1):98106. Disponível em: https://aps.ufjf.emnuvens.com.br/aps/article/vie $\mathrm{w} / 2710$

24 - Fertonani HP, Pires DEP de, Biff D, et al. Modelo assistencial em saúde: conceitos e desafios para a atenção básica brasileira. Ciênc. Saúde Colet.2015;20(6):1869-1878. Available in: http://www.scielo.br/scielo.php?pid=S14138123 2015000601869\&script=sci abstract

Nota: Este artigo não recebeu financiamento de nenhuma agência financiadora e foi o resultado de um Trabalho de Conclusão de Curso (TCC) do Programa de Pós-Graduação lato sensu da Universidade Federal de São João del Rei (UFSJ).

Recebido em: 28/01/2019

Aprovado em: 24/07/2019

Endereço de correspondência:

Marina Morato Stival

Endereço: Rua Coronel José Gonçalves de Araújo, 80. Sagrada Família.

CEP: 36220-000 - Antonio Carlos/MG - Brasil

E- mail: bruna dias 10@hotmail.com 